\title{
Flexion-distraction injuries of the thoracolumbar spine: open fusion versus percutaneous pedicle screw fixation
}

\author{
Andrew J. Grossbach, M.D., ${ }^{1}$ Nader S. Dahdaleh, M.D., ${ }^{2}$ Taylor J. Abel, M.D., ${ }^{1}$ \\ Gregory D. Woods, B.S., ${ }^{3}$ Brian J. Dlouhy, M.D., ${ }^{1}$ and Patrick W. Hitchon, M.D. ${ }^{1}$ \\ Departments of ${ }^{I}$ Neurosurgery and ${ }^{3}$ Statistics and Actuarial Science, University of Iowa, Iowa City, Iowa; \\ and ${ }^{2}$ Northwestern University, Department of Neurosurgery, Chicago, Illinois
}

\begin{abstract}
Object. Flexion-distraction injuries occur due to distractive forces causing disruption of the posterior and middle spinal columns. These fractures classically consist of a fracture line through the posterior bony elements; involvement of the posterior ligamentous complex is, however, common. Surgical treatment is often required for these unstable injuries to avoid neurological deterioration and posttraumatic kyphosis, and the surgery traditionally consists of an open posterior approach with instrumented fusion. Percutaneous pedicle screw fixation for these injuries, with the goal of minimal tissue disruption and preservation of normal anatomy while achieving adequate stabilization, has recently been reported in the literature, but to date, a direct comparative study comparing open and percutaneous fixation has not been reported. The authors report their experience treating these fractures with both techniques and review the available literature.

Methods. Patients with flexion-distraction injury who were treated between May 2003 and March 2013 were prospectively followed. American Spinal Injury Association scores and degree of kyphotic angulation were recorded at admission, discharge, and follow-up. Data regarding intraoperative blood loss and operative time were obtained from a chart review. Patients treated with open versus minimally invasive procedures were compared.

Results. The authors identified 39 patients who suffered flexion-distraction injuries and were treated at their institution during the specified period; one of these patients declined surgery. All had injury to the posterior ligamentous complex. Open surgical procedures with pedicle screw fixation and posterolateral fusion were performed in 27 patients, while 11 patients underwent minimally invasive pedicle screw placement. Overall, there was improvement in kyphotic angulation at the time of discharge as well as most recent follow-up in both the open surgery and minimally invasive surgery (MIS) groups. The authors found no significant difference in American Spinal Injury Association score or the degree of kyphotic angulation between the MIS and open surgery groups. There was a trend toward shorter operative time for the MIS group, and patients who underwent minimally invasive procedures had significantly less blood loss.

Conclusions. Minimally invasive percutaneous pedicle screw fixation appears to have similar efficacy in the treatment of flexion-distraction injuries and it allows for reduced blood loss and tissue damage compared with open surgical techniques. Therefore it should be considered as an option for the treatment of this type of injury. (http://thejns.org/doi/abs/10.3171/2013.6.FOCUS13176)
\end{abstract}

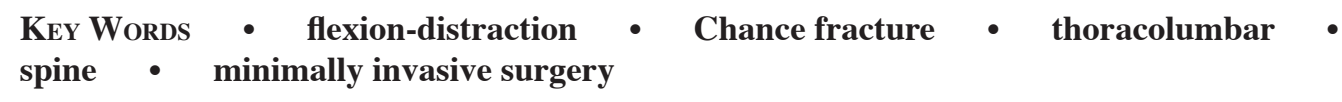

$\mathrm{F}$ LEXION-DISTRACTION injuries occur due to distractive forces leading to disruption of the posterior and middle columns of the spine. ${ }^{5}$ These injuries are frequently associated with anterior column injuries such as compression fractures, often leading to further instability or kyphosis. ${ }^{25}$ This fracture pattern was first classified by Chance, who originally described a flexion injury to the vertebrae resulting in disruption of the posterior arch system. ${ }^{3}$ These fractures classically consist of a fracture line through the spinous process, laminae, transverse

\footnotetext{
Abbreviations used in this paper: $\mathrm{AP}=$ anteroposterior; ASIA = American Spinal Injury Association; IRB = institutional review board; MIS = minimally invasive surgery; TLICS $=$ thoracolumbar injury classification system.
}

processes, pedicles, and into the vertebral body (Fig. 1), but involvement of soft tissues, such as the posterior ligamentous complex, is very common. ${ }^{1,15,22}$ The most common location for a flexion-distraction injury is around the thoracolumbar junction, although it can occur at any level of the spine. ${ }^{4,15}$ Flexion-distraction injuries account for $1 \%-16 \%$ of all thoracolumbar fractures, depending on the population examined.$^{20,28}$

Treatment of flexion-distraction injuries often requires surgical fixation and fusion. Although extension casting can be used for nondisplaced bony Chance fractures, ${ }^{1}$ surgical treatment is often required if there is damage to the posterior ligamentous complex, as the associated ligaments heal poorly despite reduction and prolonged immobilization, and conservative management 

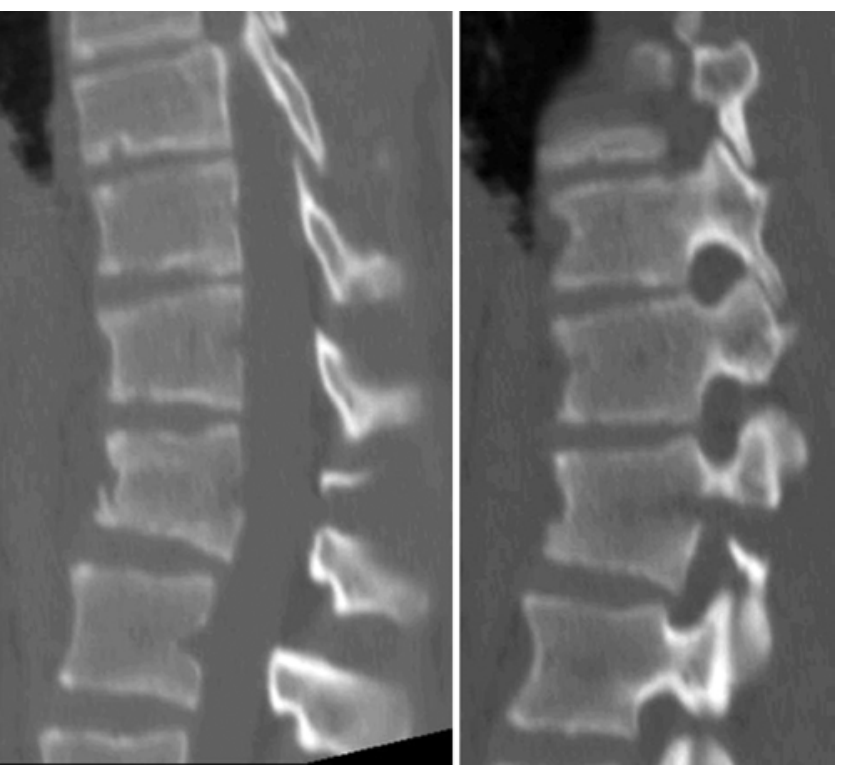

FIG. 1. Left: Midsagittal CT scan showing an L-1 fracture involving the vertebral body and extending through the spinous process. Right: Sagittal CT scan showing an L-1 fracture involving the vertebral body and extending through the pedicle posteriorly.

often results in significant kyphotic deformity and neurological deterioration. ${ }^{5,15}$ Moreover, extension bracing may be difficult for patients to tolerate, thus requiring surgical intervention. ${ }^{1}$

Recently, minimally invasive techniques, such as percutaneous pedicle screw fixation, have become more routinely used. Percutaneous pedicle screw fixation has been shown to decrease blood loss, operative time, paraspinal muscle damage, and use of postoperative analgesics. ${ }^{12,22}$ Minimally invasive percutaneous instrumentation is an option, and it is particularly suitable for unstable fractures that do not require open reduction or open decompression of the neural elements. There have been relatively few reports of percutaneous pedicle screw fixation for flexiondistraction injuries in the literature, and reports thus far are limited to primarily bony injuries.,22 This is likely due to the concern that ligamentous injuries heal poorly, thus necessitating bone grafting for fusion via open techniques. However, more recently, percutaneous pedicle screw fixation has been augmented with posterior fusion using allograft inserted after the placement of the rods.

We report our experience with the management of thoracolumbar flexion-distraction injuries with posterior ligamentous disruption over the past 10 years and compare open and percutaneous methods.

\section{Methods}

Under an IRB-approved research protocol, patients with flexion-distraction injury who were treated between May 2003 and March 2013 were followed prospectively. Neurological status was determined using the ASIA scoring system, which is based on the modified Frankel score, ${ }^{7,18}$ on admission as well as at each follow-up visit. The degree of kyphotic angulation, or Cobb angle, was measured from lateral radiographs using the rostral and caudal intact endplates on admission, at discharge, and at each follow-up visit. The residual canal was based on the AP diameter of the canal at the site of injury, expressed as a percentage of the average AP diameter at the intact levels rostral and caudal to the level of the injury. Injuries were classified using the AO classification as well as the TLICS for thoracolumbar injuries.,10,14,16,20,23,25,27,29 Total operative time, blood loss, and length of hospital stay were obtained via chart review from the surgeon's operative note, the operating room records, and the discharge summary. Results are summarized in Table 1.

\section{Results}

A total of 39 patients (30 male, 9 female) with flexion-distraction injury were treated at our institution between May 2003 and March 2013. Surgical management was recommended to all 39 patients, but one declined surgical treatment and was treated conservatively with external bracing. The average age of all 39 patients was 32 years (SD 18 years, range $14-85$ years). The mechanisms of injury included 18 motor vehicle accidents, 9 falls, 3 motorcycle accidents, 3 ATV accidents, 1 sledding accident, 1 skiing accident, 1 bicycle accident, and 1 farming accident; in addition, 1 patient was struck by a car (as a pedestrian), and 1 patient was stuck by a falling tree limb. In all cases, noncontrast MRI demonstrated injury to at least some portion of the posterior ligamentous complex (Fig. 2). The levels of injury ranged from T-4 to L-2. The most commonly injured level was L-1 (12 cases). The average residual canal after injury was $94 \%$ (range 0\%-100\%).

Open surgical procedures with pedicle screw fixation and posterolateral fusion were performed in 27 patients

TABLE 1: Comparison of patients treated with MIS versus open procedures*

\begin{tabular}{lccc}
\hline \multicolumn{1}{c}{ Variable } & MIS & Open & p Value \\
\hline $\begin{array}{l}\text { no. of patients } \\
\text { sex }\end{array} \quad 11$ & 27 & \\
$\quad$ male & 11 & 18 & \\
$\quad$ female & 0 & 9 & \\
age (yrs) & $40.1 \pm 20.3$ & $27.4 \pm 15.3$ & 0.4 \\
ASIA score & & & \\
$\quad$ at admission & $5 \dagger$ & $4.41 \pm 1.28$ & 0.31 \\
$\quad$ at follow-up & $5 \dagger$ & $4.56 \pm 1.19$ & 0.42 \\
kyphosis ( ${ }^{\circ}$ ) & & & \\
$\quad$ at admission & $6.45 \pm 3.43$ & $9.85 \pm 8.00$ & 0.23 \\
$\quad$ at follow-up & $1.45 \pm 7.98$ & $6.26 \pm 8.48$ & 0.10 \\
operative time (mins) & $195 \pm 42$ & $257 \pm 101$ & 0.07 \\
blood loss (ml) & $93.6 \pm 66.2$ & $498 \pm 415$ & 0.003 \\
no. of levels instrumented & $3.8 \pm 0.8$ & $4.7 \pm 1.2$ & 0.08 \\
hospital stay (days) & $7.6 \pm 3.8$ & $11.2 \pm 7.0$ & 0.12 \\
\hline
\end{tabular}

* Values represent numbers of patients or means \pm SDs unless otherwise indicated.

$\dagger$ No SD is given because the score was 5 for all patients in the group. 

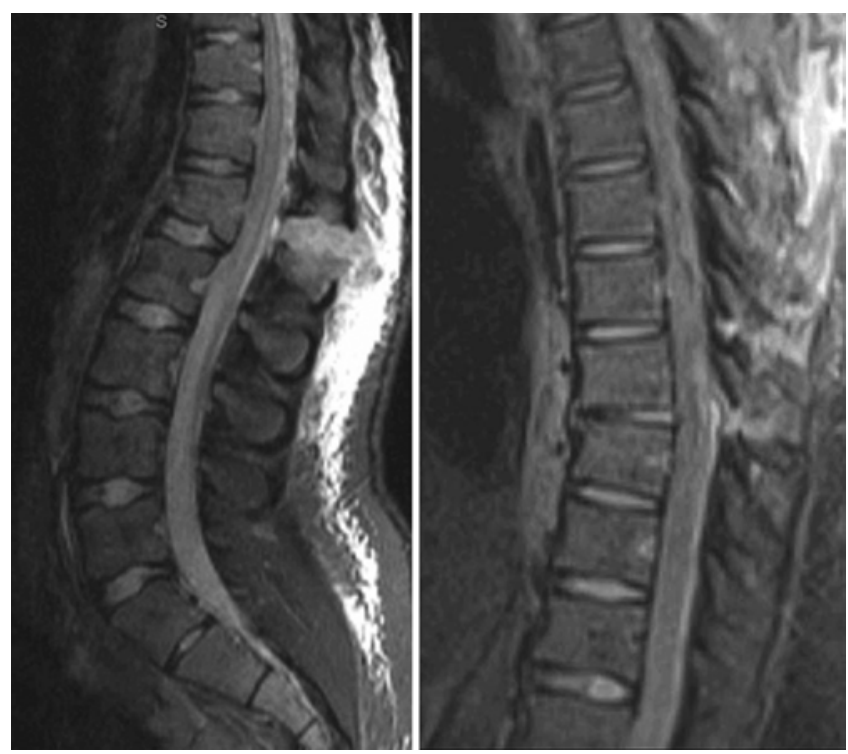

FIG. 2. Left: Midsagittal STIR MR image showing an L-1 fracture and highlighting the disruption of the posterior ligaments, including the ligamentum flavum and supraspinous ligament. Right: Midsagittal STIR MR image showing disruption of the ligamentum flavum, intraspinous ligament, and supraspinous ligament at T8-9.

(Fig. 3) and minimally invasive percutaneous pedicle screw fixation (MIS) without bony fusion was performed in 11 (Fig. 4). Twenty-four patients underwent fusion at least 2 levels above and 2 levels below the injured level. Construct length was based on the discretion of the operating surgeon, considering the level of fragmentation and comminution of the vertebral body (Fig. 5). Patients with associated fractures that compromised the anterior column support, such as burst fractures, were treated with longer-segment instrumentation. All but one of the surgi-
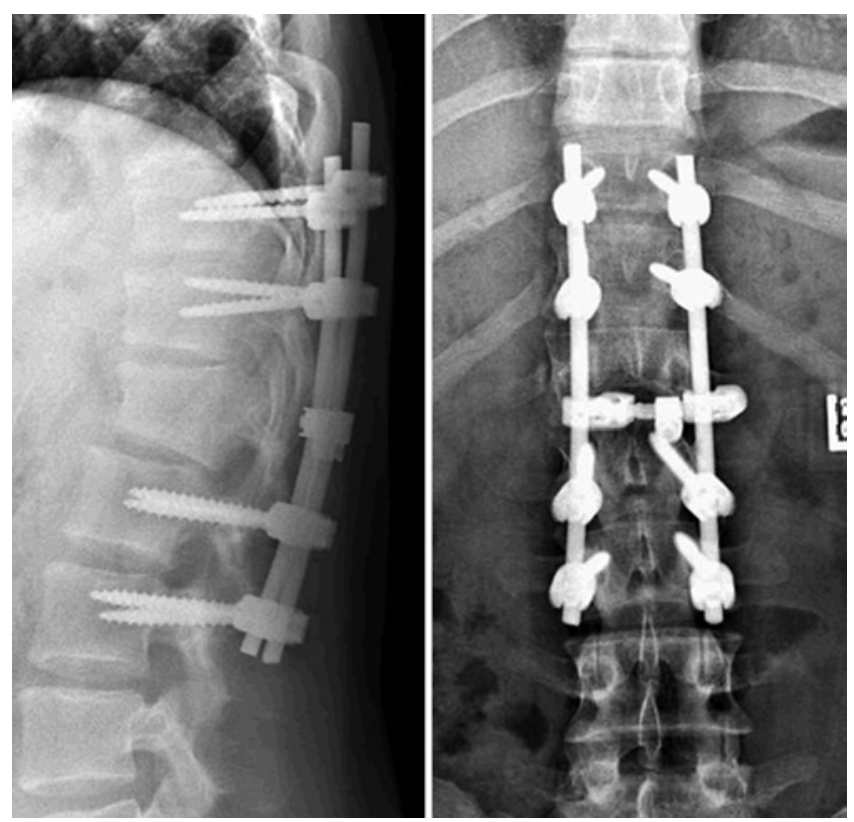

FIG. 3. Postoperative lateral (left) and AP (right) radiographs obtained after open T11-L3 posterolateral fusion with pedicle screw fixation of L-1 flexion-distraction injury.
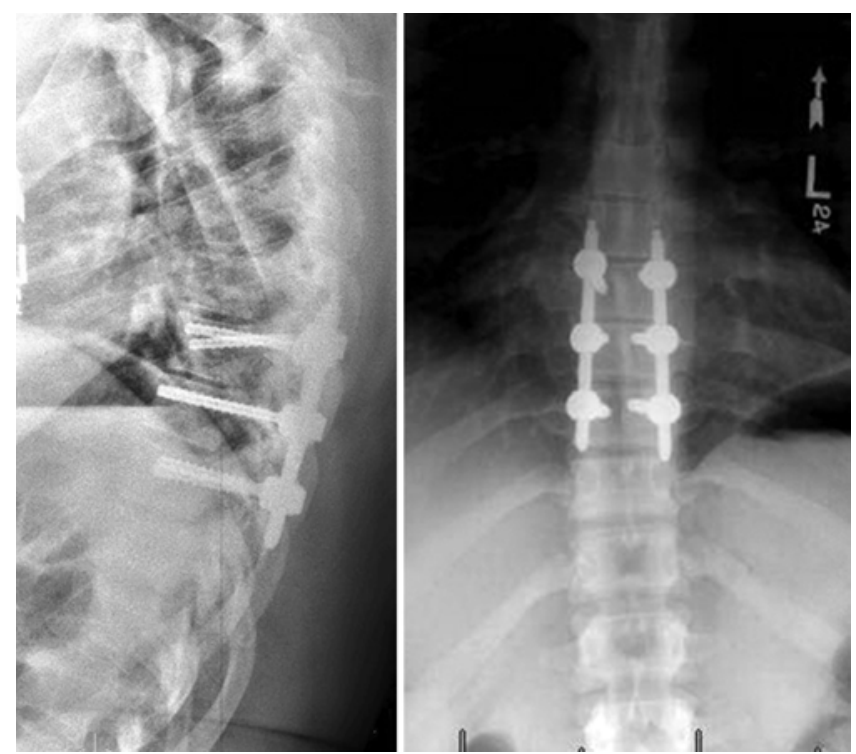

FIG. 4. Postoperative lateral (left) and AP (right) radiographs obtained after MIS T8-10 pedicle screw fixation of flexion-distraction injury.

cally treated patients underwent surgery within 7 days of injury. The one patient whose surgery was delayed underwent surgery 15 days after injury as his condition was not stable enough until this point due to associated injuries, including traumatic brain injury and hemoperitoneum. Patients with incomplete spinal cord injuries all underwent surgical decompression within 24 hours of admission. No patient showed neurological deterioration prior to being cleared for surgery. The mean duration of follow-up was 18.5 months for the open group and 9 months in the MIS group. Patients treated with MIS procedures were significantly older (mean age $40.1 \pm 20.3$ years) than patients treated with open procedures (mean age $27.4 \pm$ 15.3 years, $\mathrm{p}=0.04$ ).

The ASIA score was converted to a numerical system to aid in statistical comparison $(1=\mathrm{A}, 5=\mathrm{E})$. The average ASIA score at admission in the open surgery group was 4.41 (range 1-5, SD 1.28); all patients in the MIS group had ASIA scores of 5. The average ASIA score in the open surgery group improved to 4.56 at follow-up (range $1-5, \mathrm{SD} 1.19)$. The between-groups difference was not significant at admission ( $\mathrm{p}=0.31)$ or follow-up $(\mathrm{p}=0.42)$. The average kyphotic angulation at admission was $9.85^{\circ}$ (range $-12^{\circ}$ to $25^{\circ}, \mathrm{SD} 8.00^{\circ}$ ) in the open surgery group and $6.45^{\circ}$ (range $1^{\circ}-10^{\circ}$, SD $3.43^{\circ}$ ) in the MIS group (not significantly different, $\mathrm{p}=0.23$ ). The average kyphotic angulation improved to $6.26^{\circ}$ (range $-20^{\circ}$ to $19^{\circ}$, SD $8.48^{\circ}$ ) in the open group and to $1.45^{\circ}$ (range $-9^{\circ}$ to $18^{\circ}$, $\mathrm{SD}=7.98^{\circ}$ ) in the MIS group, but the between-groups difference was not statistically significant $(p=0.10)$. The difference between the kyphotic angulation measured during the immediate postoperative period and at followup was not significant in either the open surgery $(p=0.69)$ or the MIS group $(\mathrm{p}=0.40)$.

The total operative time averaged 195 minutes in the MIS group (range 139-280 minutes, SD 42 minutes) and 257 minutes in the open surgery group (range 132-479 


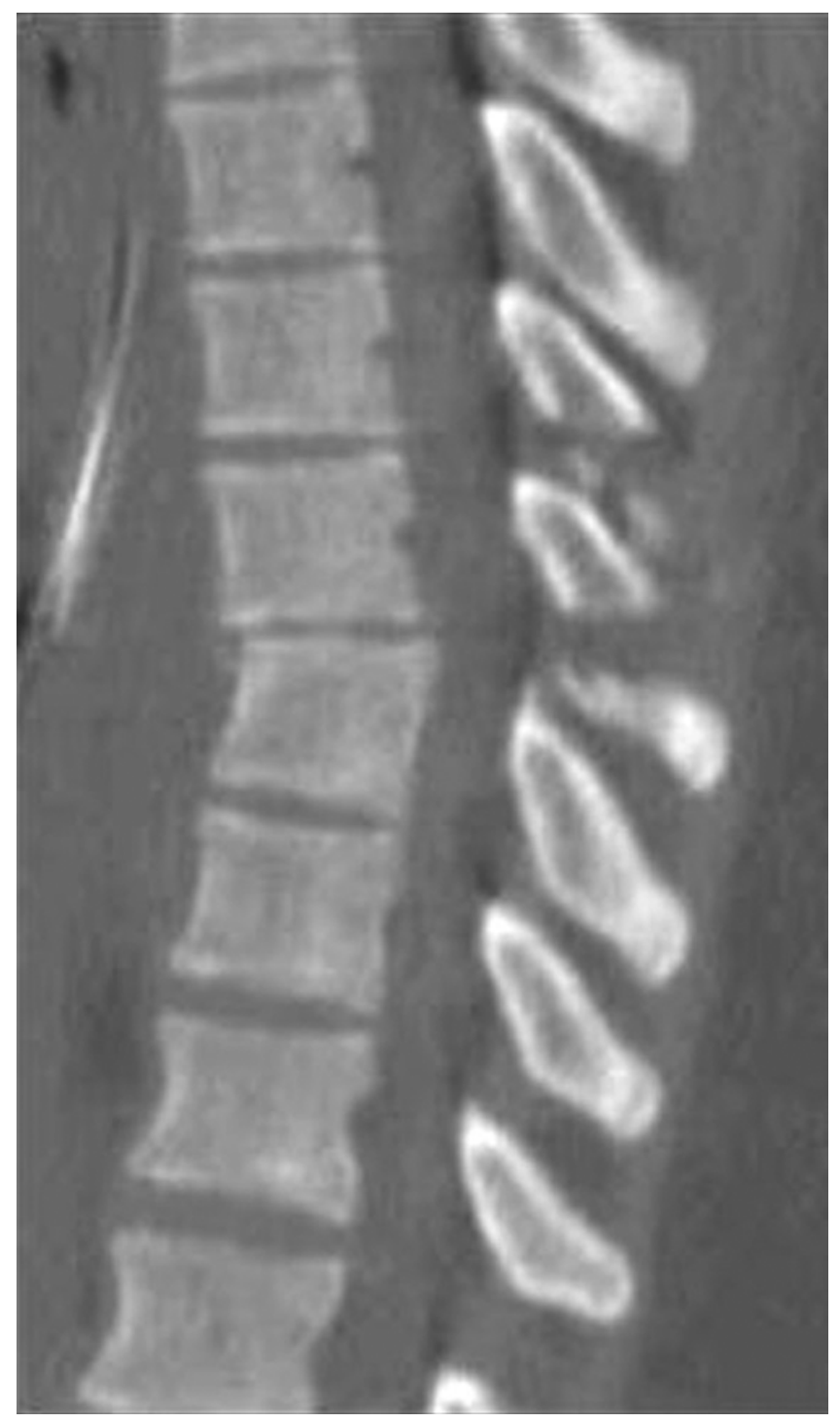

FIG. 5. Midsagittal CT scan showing a flexion-distraction injury that has caused a fracture of the T- 9 vertebral body extending posteriorly through the $T-8$ spinous process.

minutes, SD 101 minutes). There was a trend toward shorter operative times in the MIS group, but the difference did not achieve statistical significance $(p=0.07)$. The exact operative time was unavailable in 13 patients, all in the open surgery group. One patient underwent anterior cervical fusion for a separate injury during the same procedure, and this patient was omitted from the operative time analysis because the exact time of the thoracolumbar fusion could not be determined. The average blood loss was $93.6 \mathrm{ml}$ in the MIS group (range 10-200 $\mathrm{ml}$, SD $66 \mathrm{ml}$ ) and $498 \mathrm{ml}$ (range 150-1500 ml, SD 415 $\mathrm{ml}$ ) in the open surgery group. This difference was significant $(\mathrm{p}=0.003)$. Intraoperative blood loss data were not available for 6 patients, all in the open surgery group. The patient who underwent anterior cervical fusion was again excluded from this analysis as the amount of blood loss from each procedure could not be determined. Although the average number of levels instrumented was greater in the open surgery group, the between-groups difference did not achieve significance (MIS group mean $3.8 \pm 0.75$, range $3-5$ levels; open surgery group mean 4.7 \pm 1.16 , range $2-7$ levels; $p=0.08)$. The average hospital stay was 7.6 days (range 4-17 days, SD 3.8 days) for patients treated with MIS and 11.2 days for patients treated with open procedures (range 4-29 days, SD 7.0 days); this difference was not statistically significant $(p=0.12)$. The length of stay was often influenced by associated injuries.

Of our patients, 34 had TLICS scores of 7, 4 had a score of 10 , and 1 had a score of 9 . There was a mix of AO classifications, however, the most common was B1.2 injuries with the disruption of the posterior elements that was primarily ligamentous with an associated fracture of the vertebral body.

Surgical complications included a wound infection in 1 patient in the open surgery group with methicillinsensitive Staphylococcus aureus that required 10 weeks of intravenous antibiotic therapy and 2 patients who required revision for misplaced pedicle screws-one of whom was in the MIS group. The patient who declined surgery has persistent back pain and progression of kyphosis from $8^{\circ}$ on initial admission to $32^{\circ}$ at the 5-month follow-up visit. The patient was again offered surgery at that time but again declined. He remained neurologically intact. Two patients underwent subsequent removal of their MIS instrumentation without complication after the healing of their injuries, thus eliminating any lossof-motion segments. Neither patient has had subsequent progression of kyphosis following removal of the instrumentation. Although our follow-up period was relatively short, there were no cases of construct failure, kyphosis, or gibbus deformity.

\section{Discussion}

In 1948, Chance described a flexion injury to the vertebrae that resulted in a disruption of the posterior arch system. ${ }^{3}$ These fractures classically consist of a bony fracture line through the spinous process, laminae, transverse processes, pedicles, and into the vertebral body; however, involvement of soft tissues such as the posterior ligamentous complex is common. ${ }^{15,24}$ The most common location for flexion-distraction injuries is the thoracolumbar junction, ${ }^{9}$ which is consistent with our findings.

The management of flexion-distraction injuries often necessitates the use of posterior instrumentation and fusion, as conservative management may lead to kyphotic

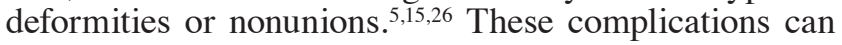
in turn lead to pain or neurological deterioration. ${ }^{11,21}$ Conservative management of purely osseous injuries with extension casting or bracing may be attempted given their ability to heal compared with ligamentous injuries; however, this may be difficult for the patient to tolerate. ${ }^{1,13,22}$ The goal of surgical fixation includes stabilization of the spine, correction of focal kyphosis, prevention of progressive kyphosis, as well as decompression of neurological structures when appropriate. ${ }^{11}$ Various surgical methods have been described for thoracolumbar flexion-distraction injuries., ${ }^{1,6,8}$ In 2004 Verlaan et al. performed a review of articles published between 1970 and 2001 that 
compared surgical techniques for traumatic thoracolumbar injuries. ${ }^{28}$ The study population included 30 patients who had flexion-distraction injuries. The authors found that none of the surgical techniques that were used were able to maintain the corrected kyphotic angle, or Cobb angle. ${ }^{11,28}$ Many of the earlier studies used hooks and rods for posterior stabilization, devices that today have largely been replaced by the use of pedicle screws. In 2008, Joseph et al. evaluated 15 cases in which posterior stabilization using pedicle screws and rods was performed for the treatment of thoracic spine flexion-distraction injuries. ${ }^{11}$ They found that the average kyphosis was improved from $19.6^{\circ}$ preoperatively to $5.73^{\circ}$ postoperatively, a statistically significant difference, and that the degree of kyphosis had increased to $7.87^{\circ}$ at last follow-up, an increase that was not statistically significant. The average time to last follow-up was 16.1 months. ${ }^{11}$ The authors suggest that thoracic flexion-distraction injury may be amenable to this single surgical approach in most cases.

In the past decade, percutaneous pedicle screw fixation has increased in popularity and the indications have expanded. 1,17,19,22 The main advantage of percutaneous pedicle screws is reduction of soft tissue dissection and muscle damage, intraoperative blood loss, operative time, and requirement for postoperative analgesics..$^{12,17,19,22}$ Percutaneous methods do not allow for direct decompression of neural elements; however they may allow for decompression of neural elements using ligamentotaxis via distraction maneuvers on the percutaneous screws. Prior reports of percutaneous pedicle screw fixation for the treatment of flexion-distraction injuries show promising results; however, they are primarily limited to bony Chance fractures. ${ }^{1,22}$

Percutaneous approaches do not allow for posterolateral bone grafting in the traditional sense, but application of allograft around the screws can be possible using a nasal speculum or similar instrument. The use of bone grafting, however, has come into question when dealing with other fracture types, such as burst fractures. ${ }^{19}$ Because ligamentous healing in flexion-distraction injuries involving the posterior ligamentous complex is slower than bony healing, there has been a reluctance to use fixation techniques that do not include bone grafting and fusion.

To our knowledge, there have been no reports of percutaneous pedicle screw instrumentation for treatment of flexion-distraction injuries with a ligamentous injury component. As noted in our results, all patients in our series had disruption of the posterior ligamentous complex. There was a slight increase in kyphosis at follow-up in the MIS group, but this was not statistically significant when compared with the degree of kyphosis at admission or at discharge, or when compared with the degree of kyphosis in the open surgery group. Our average duration of follow-up in the MIS group (11.8 months) was similar to that in previously reported cases. ${ }^{1,22}$ Removal of instrumentation after healing of the injured segments is an option, and removal serves to preserve the patient's motion segments. In our practice, if a patient is not having postoperative pain, hardware failure, or prominence of their hardware, we usually feel that they would not benefit from an additional procedure to remove the instrumenta- tion. If these problems do occur, a discussion is held with the patient regarding hardware removal. However, timing of instrumentation removal is less clear-cut in the cases of ligamentous injury than in cases of primarily osseous injury, but removal is not recommended prior to at least 1 year in the case of ligamentous injury. Two patients in our series opted for removal of the instrumentation. In our study population, patients treated with minimally invasive procedures had significantly less blood loss, a finding that is consistent with the literature. ${ }^{12,17,19,22}$ There was a trend toward reduced operative times with MIS procedures, although this did not achieve significance and could have been secondary to the trend of fewer levels instrumented in the MIS group. When dealing with osseous injuries, bony healing is more easily assessed using CT scans. Although promising, given the relative paucity of long-term data regarding MIS procedures as a treatment for flexion-distraction injuries, no definitive conclusions can be made; however, minimally invasive fixation should be considered as an option.

\section{Conclusions}

Flexion-distraction injuries involving injury to the posterior ligamentous complex should be treated operatively. Our experience, as well as the literature, shows that a posterior approach with instrumentation is sufficient to restore stability, correct deformity, and decompress the neural elements. Percutaneous pedicle screw fixation may be considered as an option in neurologically intact patients with flexion-distraction injuries where there is no need for neural decompression, even in the face of ligamentous injury. However, further studies are needed to assess the long-term outcome of patients treated with percutaneous pedicle screw fixation compared with traditional open instrumented fusion techniques.

\section{Disclosure}

Dr. Hitchon reports receiving support from DePuy Spine for clinical or research efforts not related to this study.

Author contributions to the study and manuscript preparation include the following. Conception and design: Grossbach, Hitchon. Acquisition of data: Grossbach, Hitchon. Analysis and interpretation of data: Grossbach. Drafting the article: Grossbach. Critically revising the article: Grossbach, Dahdaleh, Abel, Dlouhy, Hitchon. Reviewed submitted version of manuscript: all authors. Approved the final version of the manuscript on behalf of all authors: Grossbach. Statistical analysis: Grossbach, Woods. Study supervision: Hitchon.

\section{References}

1. Beringer W, Potts E, Khairi S, Mobasser JP: Percutaneous pedicle screw instrumentation for temporary internal bracing of nondisplaced bony Chance fractures. J Spinal Disord Tech 20:242-247, 2007

2. Bono CM, Vaccaro AR, Hurlbert RJ, Arnold P, Oner FC, Harrop J, et al: Validating a newly proposed classification system for thoracolumbar spine trauma: looking to the future of the thoracolumbar injury classification and severity score. J Orthop Trauma 20:567-572, 2006

3. Chance GQ: Note on a type of flexion fracture of the spine. $\mathbf{B r}$ J Radiol 21:452-453, 1948 


\section{A. J. Grossbach et al.}

4. Chapman JR, Agel J, Jurkovich GJ, Bellabarba C: Thoracolumbar flexion-distraction injuries: associated morbidity and neurological outcomes. Spine (Phila Pa 1976) 33:648-657, 2008

5. Denis F: The three column spine and its significance in the classification of acute thoracolumbar spinal injuries. Spine (Phila Pa 1976) 8:817-831, 1983

6. Finkelstein JA, Wai EK, Jackson SS, Ahn H, Brighton-Knight M: Single-level fixation of flexion distraction injuries. J Spinal Disord Tech 16:236-242, 2003

7. Frankel HL, Hancock DO, Hyslop G, Melzak J, Michaelis LS, Ungar GH, et al: The value of postural reduction in the initial management of closed injuries of the spine with paraplegia and tetraplegia. I. Paraplegia 7:179-192, 1969

8. Gertzbein SD, Court-Brown CM: Flexion-distraction injuries of the lumbar spine. Mechanisms of injury and classification. Clin Orthop Relat Res 227:52-60, 1988

9. Gumley G, Taylor TKF, Ryan MD: Distraction fractures of the lumbar spine. J Bone Joint Surg Br 64:520-525, 1982

10. Holdsworth FW: Fractures, dislocations, and fracture-dislocations of the spine. J Bone Joint Surg 52:1534-1551, 1970

11. Joseph SA Jr, Stephen M, Meinhard BP: The successful shortterm treatment of flexion-distraction injuries of the thoracic spine using posterior-only pedicle screw instrumentation. J Spinal Disord Tech 21:192-198, 2008

12. Kim DY, Lee SH, Chung SK, Lee HY: Comparison of multifidus muscle atrophy and trunk extension muscle strength: percutaneous versus open pedicle screw fixation. Spine (Phila Pa 1976) 30:123-129, 2005

13. Krompinger WJ, Fredrickson BE, Mino DE, Yuan HA: Conservative treatment of fractures of the thoracic and lumbar spine. Orthop Clin North Am 17:161-170, 1986

14. Lee JY, Vaccaro AR, Lim MR, Oner FC, Hulbert RJ, Hedlund $\mathrm{R}$, et al: Thoracolumbar injury classification and severity score: a new paradigm for the treatment of thoracolumbar spine trauma. J Orthop Sci 10:671-675, 2005

15. Liu YJ, Chang MC, Wang ST, Yu WK, Liu CL, Chen TH: Flexion-distraction injury of the thoracolumbar spine. Injury 34:920-923, 2003

16. Magerl F, Aebi M, Gertzbein SD, Harms J, Nazarian S: A comprehensive classification of thoracic and lumbar injuries. Eur Spine J 3:184-201, 1994

17. Mikles MR, Stchur RP, Graziano GP: Posterior instrumentation for thoracolumbar fractures. J Am Acad Orthop Surg 12:424-435, 2004

18. Mirza SK, Mirza AJ, Chapman JR, Anderson PA: Classifications of thoracic and lumbar fractures: rationale and supporting data. J Am Acad Orthop Surg 10:364-377, 2002

19. Ni WF, Huang YX, Chi YL, Xu HZ, Lin Y, Wang XY, et al: Percutaneous pedicle screw fixation for neurologic intact thoracolumbar burst fractures. J Spinal Disord Tech 23:530537,2010
20. Patel AA, Vaccaro AR, Albert TJ, Hilibrand AS, Harrop JS, Anderson DG, et al: The adoption of a new classification system: time-dependent variation in interobserver reliability of the thoracolumbar injury severity score classification system. Spine (Phila Pa 1976) 32:E105-E110, 2007

21. Ramieri A, Domenicucci M, Cellocco P, Raco A, Costanzo G: Effectiveness of posterior tension band fixation in the thoracolumbar seat-belt type injuries of the young population. Eur J Spine 18 (Suppl 1):S89-S94, 2009

22. Schizas C, Kosmopoulos V: Percutaneous surgical treatment of chance fractures using cannulated pedicle screws. Report of two cases. J Neurosurg Spine 7:71-74, 2007

23. Schweitzer KM Jr, Vaccaro AR, Lee JY, Grauer JN: Confusion regarding mechanisms of injury in the setting of thoracolumbar spinal trauma: a survey of The Spine Trauma Study Group (STSG). J Spinal Disord Tech 19:528-530, 2006

24. Smith WS, Kaufer H: Patterns and mechanisms of lumbar injuries associated with lap seat belts. J Bone Joint Surg Am 51:239-254, 1969

25. Vaccaro AR, Lehman RA Jr, Hurlbert RJ, Anderson PA, Harris M, Hedlund R, et al: A new classification of thoracolumbar injuries: the importance of injury morphology, the integrity of the posterior ligamentous complex, and neurologic status. Spine (Phila Pa 1976) 30:2325-2333, 2005

26. Vaccaro AR, Silber JS: Post-traumatic spinal deformity. Spine (Phila Pa 1976) 26 (24 Suppl):S111-S118, 2001

27. Vaccaro AR, Zeiller SC, Hulbert RJ, Anderson PA, Harris M, Hedlund R, et al: The thoracolumbar injury severity score: a proposed treatment algorithm. J Spinal Disord Tech 18:209215,2005

28. Verlaan JJ, Diekerhof CH, Buskens E, van der Tweel I, Verbout AJ, Dhert WJ, et al: Surgical treatment of traumatic fractures of the thoracic and lumbar spine: a systematic review of the literature on techniques, complications, and outcome. Spine (Phila Pa 1976) 29:803-814, 2004

29. Whang PG, Vaccaro AR, Poelstra KA, Patel AA, Anderson DG, Albert TJ, et al: The influence of fracture mechanism and morphology on the reliability and validity of two novel thoracolumbar injury classification systems. Spine (Phila Pa 1976) 32:791-795, 2007

Manuscript submitted April 15, 2013.

Accepted June 6, 2013.

Please include this information when citing this paper: DOI: 10.3171/2013.6.FOCUS13176.

Address correspondence to: Andrew J. Grossbach, M.D., Department of Neurosurgery, University of Iowa Hospitals and Clinics, 200 Hawkins Dr., Iowa City, IA 52245. email: andrew-grossbach@ uiowa.edu. 